\title{
A DEVIATION FROM STANDARD QUALITY APPROACH FOR CHARACTERISATION OF SURFACE WATER QUALITY
}

\author{
A. MUKHERJEE, S. SEN \& S.K. PAUL \\ Architecture and Regional Planning, IIT Kharagpur, India.
}

\begin{abstract}
Classification of water bodies into various classes of water use is a multi-criteria decision-making problem. Water Quality Index (WQI) and Analytic Hierarchy Process (AHP) were successfully used to assess overall water quality, but are not able to evaluate level of acceptability of water for specific use. Our objective is to develop a method of water quality assessment to evaluate the level of acceptability of a water body for specific use and to provide degree of potential effect of individual parameter on its overall quality. Here, AHP was modified and used to rank water bodies based on their quality. Modified AHP gave acceptable ranking of water bodies; but it failed to identify the reasons for what a waterbody got its corresponding rank. Therefore, a new approach of water quality assessment, named 'Deviation from Standard Quality (DSQ)' was developed. Calculation of positive or negative deviation from the desired threshold of water quality parameters is the key method of this approach. It denotes whether water could be used directly for the desired purpose or for which parameters and to what extent purification is required. We found inclusion or exclusion of any parameter had low sensitivity in evaluating ranking of the waterbodies by the DSQ method. This method was statistically validated. Empirical validation was done considering the field data obtained from Saraswati sub-watershed, Hugli, West Bengal. Keywords: alternative, analytic hierarchy process, deviation, index, parameter, water quality, waterbody, wateruse.
\end{abstract}

\section{INTRODUCTION}

Assessment of existing water quality is the first step of wise use of waterbodies; determination of the designated use based on the result of water quality assessment is the next step. Designated use of a waterbody should be the highest attainable use and should consider social demand for its existing or desired use. If the existing or desired use is not attainable as per the authorized standards, immediate restoration is needed. Therefore, determination of the level of acceptability of a waterbody for a specific use is required.

Since 1960s, Water Quality Index (WQI) served as an important tool in water quality assessment [1-3]. The first attempt to categorise water according to its degree of purity was made by Horton [4] and a general WQI was proposed by Brown et al. [5]. Thereafter, a number of water quality indices (WQIs) were developed worldwide [6-9]. Review of different WQIs was carried out by various authors $[2,3,10,11]$. Most of the attempts in developing WQIs took the approach of expert opinion that included a subjective constant $[12,13]$. Many researchers took initiatives to develop WQIs with objective approach, like statistical indices those are not considered personal opinions regarding comparative weights of different parameters to be analysed [14-16]. The statistical methods developed till today had some other limitations. The 'objective water quality index' proposed by Harkins [14] was not suitable for 
determining potential pollution in water. Stoner [17] attempted to prepare water quality indices for two specific uses: public water supply and irrigation, but failed to provide information on distribution and concentration of each parameter and the degree of treatment required for remedial measures.

Use of AHP, a widely used approach in multi-criteria decision making proposed by Saaty [18] came up as an alternative way to reduce subjectivity and increase conciseness in water quality assessment [19-21]. Karbassi et al. [22] used AHP to determine weights of different parameters of water quality. The authors [23-25] applied AHP in natural resources allocation and evaluation of environmental impacts. In lieu of AHP, some authors $[16,26-29]$ used fuzzy AHP that could deal with vague data set in the process of decision making.

Thus, WQI and analytic hierarchy process (AHP) were successfully used to assess overall quality of water, but were not capable enough of evaluating water quality for specific use. Our objective of this study is to develop a method of water quality assessment that is able to evaluate level of acceptability of a waterbody for specific use and provide degree of potential effect of individual parameter on its overall quality.

\section{MATERIALS AND METHODS}

\subsection{Study area}

The study area selected was the sub-watershed of Saraswati river basin that lied within the domain of Chandannagar and Srirampore sub-division of Hugli district, West Bengal (Fig. 1). Historically, the river Saraswati had a great importance on the economy of this region [30]. However, the present channel of Saraswati lies low as a dead river. The DVC (Damodar Valley Corporation) canal that is flowing from north-west to east of the study area has been serving as the main life-line for agricultural and domestic activities in rural areas, apart from groundwater use. Existence of both urbanized settlements with high population density, some medium scale industries (at the eastern part) and rural settlements with medium population density, extensive agriculture, orchards farming (at the western part) side-by-side give the unique characteristics to the study area.

\subsection{Selection of parameters and Collection of water samples}

Two issues were considered for the selection of parameters; first, the targeted specific uses of water: water that could be consumed directly, i.e. potable water (class P) and water that could only be consumed after conventional treatment followed by disinfection, i.e. non-potable water (class NP); secondly, available instruments or laboratory equipment to measure the parameters. Method of stratified purposeful sampling was followed for the selection of sample sites. A total of 22 samples from all kinds of water bodies present in the area were collected in sterile bottles on May, 2014. They were tested for the selected 15 parameters. Six of them were measured in situ using digital oxygen meter for measuring dissolve Oxygen (DO) and temperature and OAKTON multi-parameter tester-35 to measure temperature, $\mathrm{pH}$, electric conductivity (EC), Total dissolved solids (TDS) and salinity. The other nine parameters viz. turbidity, fluoride, ammonia, residual chlorine, nitrate, iron, total hardness, chlorides, and phosphorous were tested in laboratory using Jal-TARA water testing kit. All experiments were completed within 48 hours of collection. The locations of the water sample 


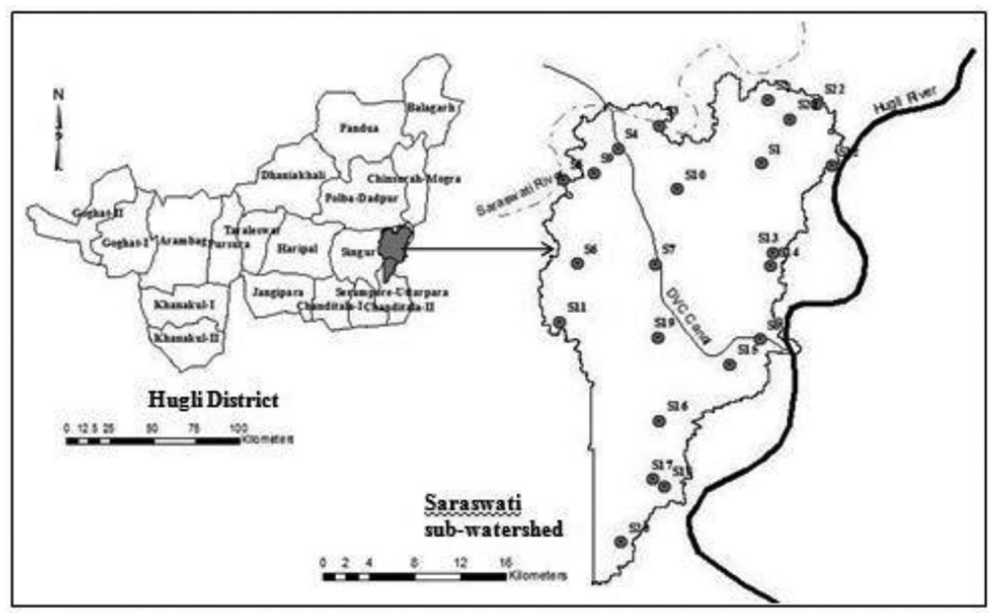

Figure 1: Location map of the study area.

sites with its corresponding coordinates collected on-site with the help of hand-held GPS. The base map of the study area was derived by overlying the vector of Saraswati sub-watershed that was delineated in Soil and Water Assessment Tool (SWAT) using SRTM-DEM over raster image of Arc-Globe online, Fig. 1.

\subsection{Water quality assessment using modified analytic hierarchy process}

AHP is an objective mathematics that can process the subjective and personal preferences of an individual or group in the process of multi-criteria decision making [31, 32]. Use of AHP in water quality assessment is helpful because it can derive relative priorities of (n) number of alternatives for several criteria having different types of scales [33] and does not need a complete database [34].

Here, AHP was modified to exclude weight factor and used to get relative ranking of waterbodies based on their water quality. A theoretical clarification denoting the modifications are discussed herein after.

\subsubsection{Developing a complete hierarchy}

When each level of a hierarchy is connected to all elements in the next higher level, it is defined as a complete hierarchy [18, 31]. For our study, a complete hierarchy for priorities of water samples was developed (Fig. 2). The first hierarchy level had a single criterion, i.e. class NP. The second hierarchy level had seven sub-criteria: DO, pH, TDS, fluoride, nitrate, iron and chloride (Table 1.) Usually, their priorities were estimated from a pair-wise comparison matrix with respect to the criteria of the first level; but here, we assumed that they have equal priority for class NP. We did it intentionally for two reasons. Firstly, we choose those parameters that had already selected as important criteria for class $\mathrm{C}$ designated use by Central Pollution Control Board, India (Table 1) and secondly, to make the whole process free from the main disadvantage of AHP technique: 'dependency on expert knowledge' [34]. The collected water samples were placed as alternatives in the third level of hierarchy. Their priorities according to their relative goodness for each sub-criterion were derived from pairwise comparison matrix to obtain the overall priorities in the final step. 


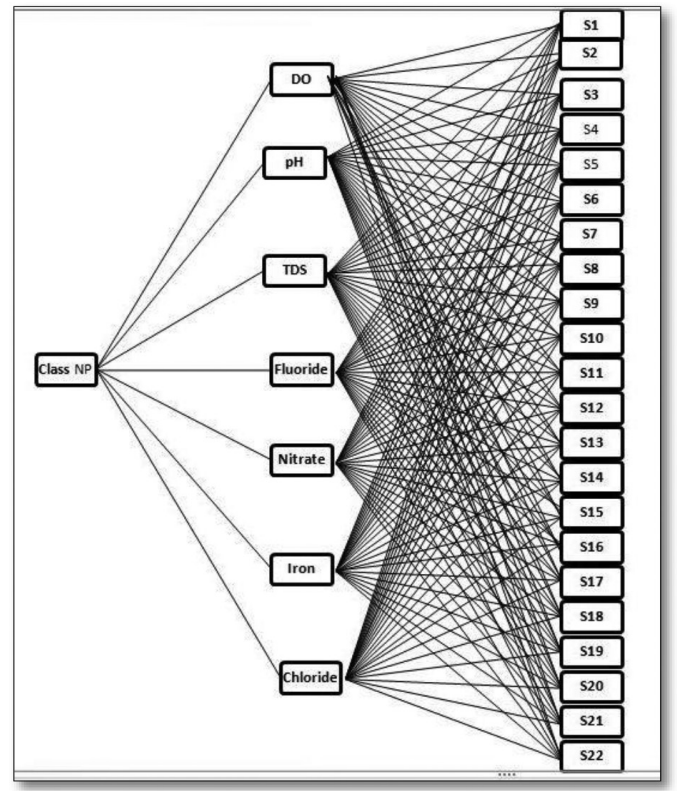

Figure 2: The complete hierarchy of AHP for priorities of water samples.

Table 1: Desirable limits of parameters for Class P and Class NP use of water.

\begin{tabular}{|c|c|c|}
\hline Parameters & Class $\mathbf{P} *$ & Class NP* \\
\hline Temp. $\left({ }^{\circ} \mathrm{C}\right)$ & N.M.* & N.M. \\
\hline $\mathrm{DO}(\mathrm{mg} / \mathrm{l}), \mathrm{min}$ & 6 & 4 \\
\hline $\mathrm{pH}$ & 6.5-8.5-- NO Relaxation & $6.5-9.0$ \\
\hline $\mathrm{EC}(\mu \mathrm{S})$, micromhos/cm, max & 300 & N.M. \\
\hline TDS (ppm) mg/l, max & $500-2,000$ & 1,500 \\
\hline Salinity (ppm) & N.M. & N.M. \\
\hline Turbidity (NTU) & 5 to 10 & N.M. \\
\hline Fluoride, as $\mathrm{F}(\mathrm{mg} / \mathrm{l})$, $\max$ & $1.0-1.5$ & 1.5 \\
\hline Ammonia (mg/l), max & 0.5-No Relaxation & N.M. \\
\hline Residual Chlorine (mg/l) min & $0.2-1.0$ & N.M. \\
\hline Nitrate, as $\mathrm{NO}_{3}(\mathrm{mg} / \mathrm{l}), \max$ & 45 -No Relaxation & 50 \\
\hline Iron, as $\mathrm{Fe}(\mathrm{mg} / \mathrm{l}), \max$ & 0.3-No Relaxation & 0.5 \\
\hline Total Hardness as $\mathrm{CaCo}_{3}(\mathrm{mg} / \mathrm{l})$, max & $300-600$ & N.M. \\
\hline Chlorides, as $\mathrm{Cu}(\mathrm{mg} / \mathrm{l})$, max & $250-1,000$ & 600 \\
\hline Phosphorous (mg/l) & N.M. & N.M. \\
\hline
\end{tabular}

Source: drinking water standards of BIS and Central Pollution Control Board, India *Note: $\mathrm{NM}=$ Not Mentioned, Class $\mathrm{P}=$ Potable water use, Class NP= Non-potable water use 
2.3.2 Making clusters and selecting pivots

When alternatives are greater than 15 , it is recommended to use clusters and pivots in pairwise comparison [18, 35]. Here, the number of alternatives was 22. All alternatives were sub-divided into three or four clusters for each criterion. In each cluster, one common alternative was selected as the pivot.

2.3.3 Preparing the guiding scores and scale of comparison

AHP has three modes of scale for ranking the alternatives: relative, absolute and benchmarking $[18,33]$. For water quality analysis, suitable mode is 'absolute' [32, 33]. Following the fundamental scale of absolute numbers proposed by Saaty [35], the sets of guiding rules were prepared (Table 2). Here, modification was done for the definitions of absolute numbers

Table 2: Parameters, intensity of difference in values and sets of guiding scores.

\begin{tabular}{|c|c|c|c|c|c|}
\hline $\begin{array}{l}\text { Parameters/ } \\
\text { Sub-criteria }\end{array}$ & $\begin{array}{l}\text { Intensity of } \\
\text { Difference }\end{array}$ & Score & $\begin{array}{l}\text { Parameters/ } \\
\text { Sub-criteria }\end{array}$ & $\begin{array}{l}\text { Intensity of } \\
\text { Difference }\end{array}$ & Score \\
\hline \multirow{8}{*}{$\begin{array}{l}\text { Dissolve } \\
\text { Oxygen (mg/l), } \\
\text { min }\end{array}$} & $\leq 0.2$ & 2 & \multirow{4}{*}{$\begin{array}{l}\text { Fluoride, as F } \\
(\mathrm{mg} / \mathrm{l}), \max \end{array}$} & $\leq 0.4$ & 3 \\
\hline & $>0.2-0.5$ & 3 & & $>0.4-0.8$ & 5 \\
\hline & $>0.5-1.0$ & 4 & & $>0.8-1.2$ & 7 \\
\hline & $>1.0-1.5$ & 5 & & $>1.2$ & 9 \\
\hline & $>1.5-2.5$ & 6 & \multirow{8}{*}{$\begin{array}{l}\text { Nitrate, as } \mathrm{NO}_{3} \\
(\mathrm{mg} / \mathrm{l}), \max \end{array}$} & $\leq 2.5$ & 2 \\
\hline & $>2.5-3.5$ & 7 & & $>2.5-5$ & 3 \\
\hline & $>3.5-4.5$ & 8 & & $>5-10$ & 4 \\
\hline & $>4.5$ & 9 & & $>10-20$ & 5 \\
\hline \multirow[t]{8}{*}{$\mathrm{pH}$} & $\leq 0.15$ & 2 & & $>20-30$ & 6 \\
\hline & $>0.15-0.45$ & 3 & & $>30-40$ & 7 \\
\hline & $>0.45-0.85$ & 4 & & $>40-50$ & 8 \\
\hline & $>0.85-1.15$ & 5 & & $>50$ & 9 \\
\hline & $>1.15-1.45$ & 6 & \multirow{4}{*}{$\begin{array}{l}\text { Iron, as Fe } \\
(\mathrm{mg} / \mathrm{l}), \max \end{array}$} & $\leq 0.2$ & 3 \\
\hline & $>1.45-1.75$ & 7 & & $>0.2-0.8$ & 5 \\
\hline & $>1.75-2.0$ & 8 & & $>0.8-1.5$ & 7 \\
\hline & $>2.0$ & 9 & & $>1.5$ & 9 \\
\hline \multirow{8}{*}{$\begin{array}{l}\text { Total Dissolve } \\
\text { Solids (ppm) } \\
\text { mg/l, max }\end{array}$} & $\leq 15$ & 2 & \multirow{8}{*}{$\begin{array}{l}\text { Chlorides, as } \\
\mathrm{Cu}(\mathrm{mg} / \mathrm{l}), \max \end{array}$} & $\leq 10$ & 2 \\
\hline & $>15-30$ & 3 & & $>10-20$ & 3 \\
\hline & $>30-45$ & 4 & & $>20-30$ & 4 \\
\hline & $>45-60$ & 5 & & $>30-40$ & 5 \\
\hline & $>60-75$ & 6 & & $>40-50$ & 6 \\
\hline & $>75-90$ & 7 & & $>50-60$ & 7 \\
\hline & $>90-105$ & 8 & & $>60-70$ & 8 \\
\hline & $>105$ & 9 & & $>70$ & 9 \\
\hline
\end{tabular}


Table 3: The fundamental scale of absolute number modified after Saaty, TL.

\begin{tabular}{lll}
\hline Score & Definition & Explanation \\
\hline 1 & Equal & Two alternatives are of same quality \\
3 & Slightly better & One is slightly better than other \\
5 & Better & One is better than other \\
7 & Much better & One is much better than other \\
9 & much more better & One is much more better than other \\
$2,4,6,8$ & Intermediate values & \\
\hline
\end{tabular}

Source: (Saaty, 2004)

mentioned in Saaty's nine points scale (Table 3). It would help consistent judgements in preparing the comparison matrix for each parameter.

\subsubsection{Construction of the pair-wise comparison matrices}

Here, a total of 25 matrices were developed. Numerical differences between two consecutive alternatives were estimated and decision was made according to the scales of intensity of difference, individually for each matrix of a sub-criterion, Tables 2 and 3.

\subsubsection{Synthesized judgement, checking consistency, aggregation of clusters}

Standardized matrix was prepared dividing each cell of the original comparison matrix by its corresponding column sum and mean of each row that represented relative weights of the alternatives was calculated. The Eigen Value Method was used to calculate the Principal Eigen value and eigen value of each alternative was calculated dividing the element of priority vector by weight vector. Matrix multiplication was performed; it gave priority vector for each cluster. Then, primary priorities were calculated for each alternative of a cluster. For cluster1, the primary priorities of all alternatives were directly considered as their overall priority. Primary priorities of cluster 2 were linked up with cluster1 by multiplying them with the ratio of the priorities of the pivot in cluster1 and cluster2. Thus, overall priorities were calculated for (n) number of clusters.

\subsubsection{Estimation of final rankings}

The set of overall priority of each sub-criterion was considered as their local priority. "The historical AHP approach adopts an additive aggregation with normalization of the sum of local priorities to unity: $\mathrm{p}_{i}=\sum_{j}$ wj.lij. Where, $\mathrm{p}_{i}=$ global priority of the alternative $i, 1_{i j}=$ local priority, $\mathrm{w}_{j}=$ weight of the criterion $j$ " $[36,37]$. But here, we assumed that every subcriterion had similar importance in maintaining quality for a specific use of water. Therefore, in this case, $\mathrm{w}_{i}=1$; so, $\mathrm{p}_{i}=\sum l i j$. The local priorities of each sub-criterion were simply added to estimate global priorities of the alternatives and they ranked in decreasing order.

\subsection{Water quality assessment for specific water use: an alternative approach}

In order to reach our objectives, a new approach of water quality assessment, named as 'Deviation from Standard Quality (DSQ)' was developed. Calculation of positive or negative deviation from the desired threshold of water quality parameter is the key method of this 
approach. Considering the reverse nature of some parameters, two separate formulae, eqns (1) and (2), were prepared which are given below:

For the parameters where larger value represents worse condition and vice-versa:

$$
\mathrm{Q}_{i}=\left(\mathrm{X}_{\mathrm{d}}-\mathrm{X}_{i}\right) /\left(\mathrm{X}_{\max }-\mathrm{X}_{\min }\right)
$$

For the parameters where larger value represents better condition and vice-versa:

$$
\mathrm{Q}_{i}=\left(\mathrm{X}_{\mathrm{i}}-\mathrm{X}_{\mathrm{d}}\right) /\left(\mathrm{X}_{\max }-\mathrm{X}_{\min }\right)
$$

Where, $X_{d}$ is the desirable standard value for a particular parameter, $X_{i}$ is the observed value of that parameter, $X_{\max }$ and $X_{\min }$ are the maximum and minimum observed value, respectively.

This approach deals with a bi-polar scale of acceptability. The composite deviation of zero represents the threshold for acceptability of a water sample for a particular purpose of use; positive increase of composite deviation denotes better condition and acceptability increases while negative increase indicates worse condition and degree of non-acceptability increases. Composite deviation of a particular water sample was calculated by summing up the deviations of all parameters selected for assessing water quality for a particular class of water use and it was used to get the final rankings of waterbodies as well as to evaluate acceptability for that specific use.

In this study, to assess water quality with DSQ method for class P 12 parameters, i.e. DO, $\mathrm{pH}, \mathrm{EC}, \mathrm{TDS}$, turbidity, fluoride, iron, residual chlorine, total hardness, chlorides, nitrate, ammonia and for class NP seven parameters, i.e. DO, $\mathrm{pH}$, TDS, fluoride, iron, nitrate, and chlorides were selected, Table 1. equation (2) was used to calculate deviations from desired limits in case of DO, $\mathrm{pH}$ and residual chlorine while for other parameters eqn. (1) was used.

\section{RESULTS AND DISCUSSION}

From literatures [38, 39], it was cleared that AHP had been accepted as a standard method in multi-criteria decision-making process, worldwide. Consistency index developed for each normalized matrix was checked with its corresponding consistency ratio, and it was observed that all matrices were consistent in judgements. Therefore, the set of priorities with respect to their superiority in quality derived through modified AHP could be used to rank the alternatives. Here, output of modified AHP supported our field experiences also. We found river Saraswati in water logged condition; water hyacinth grew extensively. It lost its identity as river to local people and was used as a wastewater disposal channel. The water samples, S3 and S5, collected from river Saraswati got the lowest rank 22nd and $20^{\text {th }}$, respectively (Table 4). The water sample S19, which was from a road-side waterbody linked to industrial wastewater channel got 21st rank, Table 4. These three water samples (S3, S5 and S19) got same ranks as above through DSQ method for class P and class NP, Table 4, both. For statistical verification, spearman's rank-order correlation was calculated and a very high degree of association (0.87) was found between the two sets of ranking resulting from modified AHP and DSQ method.

Quantitative information of global priority resulted from modified AHP could not evaluate the level of acceptability of waterbody for a specific use. Beside, local priority could not exhibit potential effect of a parameter on overall water quality. Whereas by the DSQ method, quantitative deviation of a parameter gave the reasons for what a waterbody got its corresponding rank and which parameters, to what extent needed purifying treatment. In assessing water quality for class $\mathrm{P}$ by the DSQ method, we found 18 samples had composite deviation greater than zero (Fig. 3). Among them, S12 had the maximum positive composite deviation (3.332), 
Table 4: Relative rank of water samples by modified AHP and DSQ method.

\begin{tabular}{|c|c|c|c|c|c|c|c|}
\hline \multirow[b]{2}{*}{ Alternative } & \multirow[b]{2}{*}{ Source } & \multicolumn{2}{|c|}{$\begin{array}{c}\text { Modified } \\
\text { AHP_class NP }\end{array}$} & \multicolumn{2}{|c|}{ DSQ_class P } & \multicolumn{2}{|c|}{ DSQ_class NP } \\
\hline & & $\begin{array}{l}\text { Global } \\
\text { Priority }\end{array}$ & Rank & $\begin{array}{l}\text { Composite } \\
\text { Deviation }\end{array}$ & Rank & $\begin{array}{l}\text { Compoaite } \\
\text { Deviation }\end{array}$ & Rank \\
\hline $\mathrm{S} 1$ & Pond & 2.397 & 11 & 1.374 & 15 & 6.43 & 8 \\
\hline $\mathrm{S} 2$ & Pond & 0.784 & 19 & 1.184 & 16 & 5.568 & 18 \\
\hline S3 & $\begin{array}{l}\text { Saraswati } \\
\text { River }\end{array}$ & 0.037 & 22 & -3.681 & 22 & 1.402 & 22 \\
\hline S4 & Canal & 5.54 & 3 & 3.033 & 3 & 7.152 & 2 \\
\hline S5 & $\begin{array}{l}\text { Saraswati } \\
\text { River }\end{array}$ & 0.578 & 20 & -0.582 & 21 & 4.799 & 20 \\
\hline S6 & Pond & 2.044 & 14 & 1.618 & 10 & 6.486 & 7 \\
\hline S7 & Canal & 2.678 & 10 & 2.251 & 6 & 6.128 & 11 \\
\hline S8 & Canal & 6.923 & 1 & 0.708 & 18 & 6.524 & 6 \\
\hline S9 & Tube well & 2.16 & 12 & 2.126 & 7 & 6.062 & 15 \\
\hline $\mathrm{S} 10$ & Tube well & 3.148 & 7 & 2.021 & 8 & 6.106 & 12 \\
\hline $\mathrm{S} 11$ & Tube well & 1.448 & 18 & 1.39 & 14 & 5.601 & 17 \\
\hline $\mathrm{S} 12$ & Tap water & 5.511 & 4 & 3.332 & 1 & 7.185 & 1 \\
\hline S13 & Tube well & 1.597 & 17 & -0.144 & 19 & 5.101 & 19 \\
\hline S14 & Tap water & 2.963 & 8 & 2.544 & 5 & 6.566 & 5 \\
\hline S15 & Tube well & 5.927 & 2 & 3 & 4 & 6.652 & 4 \\
\hline S16 & Tap water & 4.286 & 5 & 3.282 & 2 & 6.984 & 3 \\
\hline S17 & Tap water & 1.722 & 16 & 1.423 & 13 & 6.104 & 14 \\
\hline S18 & Tube well & 2.101 & 13 & 1.517 & 12 & 5.848 & 16 \\
\hline S19 & $\begin{array}{l}\text { Road-side } \\
\text { waterbody }\end{array}$ & 0.572 & 21 & -0.321 & 20 & 4.316 & 21 \\
\hline $\mathrm{S} 20$ & Tube well & 2.011 & 15 & 1.645 & 9 & 6.192 & 9 \\
\hline $\mathrm{S} 21$ & Tap water & 2.703 & 9 & 1.592 & 11 & 6.105 & 13 \\
\hline $\mathrm{S} 22$ & Well & 4.03 & 6 & 0.9 & 17 & 6.135 & 10 \\
\hline
\end{tabular}

*Note: Class $\mathrm{P}=$ Potable water use, Class $\mathrm{NP}=$ Non-potable water use

ranked first and acceptable for class $\mathrm{P}$ use, but needed purification treatments specifically for the three parameters, i.e. EC (-0.023), ammonia ( -0.2$)$ and residual chlorine $(-0.25)$ that had negative deviation. Remaining four samples had negative composite deviation and therefore not acceptable for class P. The sample S3 had the highest negative composite deviation 


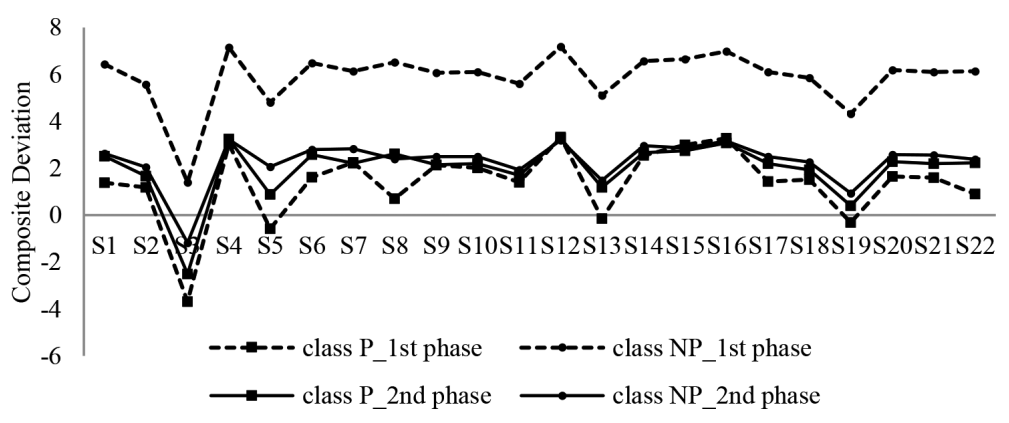

Figure 3 Composite deviation of water samples from the desired threshold of acceptability for Class P and NP in 1st and 2nd phase of analysis.

$(-3.681)$, and ranked the lowest, i.e. $22 \mathrm{nd}$. It had nine parameters with negative deviation; among them ammonia $(-1)$ had the maximum negative deviation followed by EC $(-0.988)$, iron $(-0.947)$, turbidity $(-0.7)$, TDS $(-0.605)$, DO $(-0.563)$, fluoride $(-0.556)$, total hardness $(-0.484)$ and nitrate $(-0.438)$. This information would help in remedial measures.

A second phase of analysis was carried out to refine the result of first phase analysis as well as to check the sensitivity of the DSQ method to a parameter. In case of $\mathrm{pH}$ and chloride, no obtained value ever crossed the determined threshold of class $\mathrm{P}$ and class NP. So pH and chloride were excluded in the second phase of analysis and composite deviations were recalculated. This time, only nine samples could cross the threshold of acceptability for class P (Fig. 3). In case of class NP, during the first phase of analysis, all samples had composite deviation above zero (Fig. 3). Two samples, S3 and S19 which got the lower most rank in the first phase of analysis, got negative composite deviation in second phase of analysis (Fig. 3). The findings would help in prioritizing the process of quality management over a targeted region.

Spearman's rank-order correlation was calculated between the two sets of rankings in first and second phase of analysis. The Rho values for class P (0.9819) and class NP (0.9537) indicated a very good association between the two sets of ranking. It signified that inclusion or exclusion of any parameter has very low sensitivity on estimation of overall ranking by the DSQ method. Overall, class P needs better quality of water than class NP. The result of the DSQ method in both first and second phase of analysis revealed that all samples had lower degree of acceptability for class P use than class NP use of water (Fig. 3).

\section{CONCLUSION}

This article proposed modification in the AHP technique and a new approach entitled DSQ method to assess water quality for specific water use. Modified AHP differs from AHP by excluding subjective constant and suggesting the sets of guiding for consistent judgements in developing comparison matrix. Application of AHP in the final assessment of water quality is rare approach. It only gave rankings of water samples without providing significant information on role of individual parameter on overall quality and not suitable for assessing quality for specific water use. While the DSQ method is an objective technique, flexible to set desired standard for $n$ number of parameters and therefore applicable for water quality assessment for specific use. It provides level of acceptance of a waterbody for its desired use and quantitative information on the status of individual parameter incorporated for qualitative assessment. This study suggested that the DSQ method can be used not only for water quality assessment for specific use but also can be applied for other types of pollution assessment, 
such as, air pollution. In future, experimental application of the DSQ method in qualitative assessment of various natural resources over different spatial units would establish this method as a suitable alternative tool for pollution assessment.

\section{ACKNOWLEDGMENTS}

The author, Anita Mukherjee, is thankful to Indian Institute of Technology, Kharagpur and Department of Architectural and Regional Planning of IIT Kharagpur for providing financial support and research facilities. The authors like to thank Debnarayan Mukherjee, Ranjeet Sil, Koushik Banerjee and the local inhabitants of the selected sample sites for helping in collection of water samples and field visits.

\section{REFERENCES}

[1] Brown, R.M., McClelland, N.I., Deininger, R.A. \& O'Connor, M.F., A water quality index - crashing the psychological barrier. Indicators of Environmental Quality, 1(1), pp. 173-182, 1972.

[2] Lumb, A., Sharma, T.C. \& Bibeault, J.F., A review of genesis and evolution of water quality index(WQI) and some future directions. Water Quality Exposure and Health, 3, pp. 11-24, 2011. http://dx.doi.org/10.1007/s12403-011-0040-0

[3] Poonam, T., Tanushree, B. \& Sukalyan, C., Water quality indices - important tools for water quality assessment: a review. International Journal of Advances in Chemistry, 1(1), pp. 15-28, 2013.

[4] Horton, R.K., An index number system for rating water quality. Journal of Water Pollution Control Federation, 37(3), pp. 300-306, 1965.

[5] Brown, R.M., McClelland, N.I., Deininger, R.A. \& Tozer, R.G., A water quality index do we dare? Water and Sewage Works, 117(10), pp. 339-343, 1970.

[6] Bhargava, D.S., Use of water quality index for river classification and zoning of Ganga river. Environmental Pollution Series B, Chemical and Physical, 6(1), pp. 51-67, 1983. http://dx.doi.org/10.1016/0143-148X(83)90029-0

[7] Liou, S.M., Lo, S.L. \& Wang, S.H., A generalized water quality index for Taiwan. Environmental Monitoring and Assessment, 96(1-3), pp. 35-52, 2004. http://dx.doi.org/10.1023/B:EMAS.0000031715.83752.a1

[8] Said, A., Stevens, D.K. \& Sehlke, G., An innovative index for evaluating water quality in streams. Environmental Management, 34(3), pp. 406-414, 2004. http://dx.doi.org/10.1007/s00267-004-0210-y

[9] Nasiri, F., Maqsood, I., Huang, G. \& Fuller, N., Water quality index: a fuzzy riverpollution decision support expert system. Journal of Water Resources Planning and Management, 133(2), pp. 95-105, 2007. http://dx.doi.org/10.1061/(ASCE)0733-9496(2007)133:2(95)

[10] Landwehr, J.M. \& Deininger, R.A., A comparision of several water quality indexes. Journal Water Pollution Control Federation, 48(5), pp. 954-958, 1976.

[11] Bharti, N. \& Katyal, D., Water quality indices used for surface water vulnerability assessment. International Journal of Environmental Sciences, 2(1), pp. 154-173, 2011.

[12] Smith, D.G., A better water quality indexing system for rivers and streams. Water Research, 24(10), pp. 1237-1244, 1990. http://dx.doi.org/10.1016/0043-1354(90)90047-A 
[13] Ramesh, S., Sukumaran, N., Murugesan, A.G. \& Rajan, M.P., An innovative approach of drinking water quality index - a case study from Southern Tamil Nadu, India. Ecological Indicators, 10, pp. 857-868, 2010. http://dx.doi.org/10.1016/j.ecolind.2010.01.007

[14] Harkins, R.D., An objective water-quality index. Journal Water Pollution Control Federation, 46(3), pp. 588-591, 1974.

[15] Parparov, A. \& Hambright, K.D., Composite water quality: evaluation and management feedbacks. Water Quality Research Journal of Canada, 42, pp. 20-25, 2007.

[16] Alias, M.A., Hashim, S.Z.M. \& Samsudin, S., Using fuzzy analytic hierarchy process for southern Johor river ranking. International Journal Advance Soft Computer Application, 1(1), pp. 62-76, 2009.

[17] Stoner, J.D., Water-quality indices for specific water uses. Geological Survey Circular 770, United States Department of the Interior, pp. 1-12, 1978.

[18] Saaty, T.L., A scaling method for priorities in hierarchical structures. Journal of Mathematical Psychology, 15(3), pp. 234-281, 1977. http://dx.doi.org/10.1016/0022-2496(77)90033-5

[19] Saaty, T.L., Fundamentals of Decision Making and Priority Theory with the Analytic Hierarchy Process, Rws Publications, 6, pp. 1-75, 1994.

[20] Saaty, T.L., Time dependent decision-making; dynamic priorities in the AHP/ANP: Generalizing from points to functions and from real to complex variables. Mathematical and Computer Modelling, 46, pp. 860-891, 2007. http://dx.doi.org/10.1016/j.mcm.2007.03.028

[21] Harker, P.T. \& Vargas, L.G., The theory of ratio scale estimation: saaty's analytic hierarchy process. Management Science, 33(11), pp. 1383-1403, 1987.

[22] Karbassi, A.R., Hosseini, M.M.F., Baghvand, A. \& Nazariha, M., Development of water quality index (wqi) for gorganrood river. International Journal of Environmental Research, 5(4), pp. 1041-1046, 2011.

[23] Ramanathan, R., A note on the use of the analytic hierarchy process for environmental impact assessment. Journal of Environmental Management, 63(1), pp. 27-35, 2001. http://dx.doi.org/10.1006/jema.2001.0455

[24] Schmoldt, D.L., Kangas, J., Guillermo, A. \& Pesonen, M. (eds), The Analytic Hierarchy Process in Natural Resource and Environmental Decision Making, Springer Science \& Business Media, LLC, 2001. http://dx.doi.org/10.1007/978-94-015-9799-9

[25] Patil, V.D., Sankhua, R.N. \& Jain, R.K., Analytic hierarchy process for evaluation of environmental factors for residential land use suitability. International Journal of Computational Engineering Research, 2(7), pp. 182-189, 2012.

[26] Wang, Y.M. \& Chin, K.S., Fuzzy analytic hierarchy process: a logarithmic fuzzy preference programming methodology. International Journal of Approximate Reasoning, 52(4), pp. 541-553, 2011.

http://dx.doi.org/10.1016/j.ijar.2010.12.004

[27] Raj, P.A. \& Kumar, D.N., Ranking alternatives with fuzzy weights using maximizing set and minimizing set. Fuzzy Sets and Systems, 105(3), pp. 365-375, 1999. http://dx.doi.org/10.1016/S0165-0114(97)00243-1

[28] Hao, W., Hanting, Z., Wenjuan, X. \& Jinling, Z., Evaluation of groundwater quality using improved fuzzy comprehensive assessment based on AHP. International Journal of Applied Sciences and Engineering Research, 2(3), pp. 377-384, 2013. 
[29] Chau, K., A review on integration of artificial intelligence into water quality modelling. Marine Pollution Bulletin, 52(7), pp. 726-733, 2006. http://dx.doi.org/10.1016/j.marpolbul.2006.04.003

[30] Majumdar, R.C., History of Ancient Bengal, G. Bharadwaj, pp. 308-309, 1971.

[31] Saaty, T.L. \& Vargas, L.G., Models, Methods, Concepts and Applications of the Analytic Hierarchy Process, Springer Science \& Business Media, LLC, pp. 2-46, 2012.

[32] Velasquez, M. \& Hester, P.T., An analysis of multi-criteria decision making methods. International Journal of Operations Research, 10(2), pp. 56-66, 2013.

[33] Saaty, T.L., How to make a decision: the analytic hierarchy process. European Journal of Operational Research, 48(1), pp. 9-26, 1990. http://dx.doi.org/10.1016/0377-2217(90)90057-I

[34] Nefeslioglu, H.A., Sezer, E.A., Gokceoglu, C. \& Ayas, Z., A modified analytical hierarchy process (M-AHP) approach for decision support systems in natural hazard assessments. Computers \& Geosciences, 59, pp. 1-8, 2013. http://dx.doi.org/10.1016/j.cageo.2013.05.010

[35] Saaty, T.L., Decision making - the analytic hierarchy and network processes (AHP/ ANP). Journal of Systems Science and Systems Engineering, 13(1), pp. 1-35, 2004. http://dx.doi.org/10.1007/s11518-006-0151-5

[36] Crawford, G. \& Williams, C., A note on the analysis of subjective judgment matrices. Journal of Mathematical Psychology, 29(4), pp. 387-405, 1985. http://dx.doi.org/10.1016/0022-2496(85)90002-1

[37] Ishizaka, A. \& Labib, A., Review of the main developments in the analytic hierarchy process. Expert Systems with Applications, 38(11), pp. 14336-14345, 2011. http://dx.doi.org/10.1016/j.eswa.2011.04.143

[38] Saaty, T.L., Highlights and critical points in the theory and application of the analytic hierarchy process. European Journal of Operational Research, 74(3), pp. 426-447, 1994. http://dx.doi.org/10.1016/0377-2217(94)90222-4

[39] Ghosh, D.N., Analytic hierarchy process \& TOPSIS method to evaluate faculty performance in engineering education. UNIASCIT, 1(2), pp. 63-70, 2011. 